\title{
Correction to: Climate information services, integrated knowledge systems and the 2030 agenda for sustainable development
}

Fortunate Machingura ${ }^{1,2^{*}}$, Admire Nyamwanza ${ }^{3}$, David Hulme ${ }^{1}$ and Elizabeth Stuart ${ }^{2}$

\section{Correction to: Sustainable Earth (2018) 1:1 DOI: https://doi.org/10.1186/s42055-018-0003-4}

It has been highlighted that the original article [1] contained a spelling mistake in the last name of Elizabeth Stuart. Her last name was incorrectly captured as 'Stewart' in the original article which has since been updated.

\section{Author details \\ ${ }^{1}$ Global Development Institute, University of Manchester, Oxford Road, \\ Manchester M139PL, England. 'ºverseas Development Institute, 203 Blackfriars Road, London SE1 8NJ, England. ${ }^{3}$ Human Sciences Research Council, Economic Performance and Development Unit, Merchant House Building, 116-118 Buitengrancht Street, Cape Town, South Africa.}

Received: 8 November 2018 Accepted: 8 November 2018

Published online: 28 November 2018

\section{Reference}

1. Machingura, et al. Climate information services, integrated knowledge systems and the 2030 agenda for sustainable development. Sustainable Earth. 2018;1:1. https://doi.org/10.1186/s42055-018-0003-4.

\footnotetext{
*Correspondence: fmachingura@gmail.com

${ }^{1}$ Global Development Institute, University of Manchester, Oxford Road, Manchester M139PL, England

${ }^{2}$ Overseas Development Institute, 203 Blackfriars Road, London SE1 8NJ,

England

Full list of author information is available at the end of the article
} 